\title{
Evaluation of endoscopic assisted suction coagulation adenoidectomy versus traditional curettage technique
}

\author{
Ayman Ali Abd Elfattah Ali, Mohammed Kamar Elsharnouby, Yaser Abd Elwahab Khalil, \\ Rehab Nour Eldin Mohammad Gad Allah* and Mohammed Abd Elhakeem Khalifa
}

\begin{abstract}
Background: Adenoidal hypertrophy is a common condition in children and can cause symptoms such as mouth breathing, nasal discharge, snoring, sleep apnea, and hyponasal speech. The curettage adenoidectomy has some disadvantages, especially the intranasal extension of the adenoid tissue that makes this technique inadequate. This study is conducted to evaluate and compare between assisted suction coagulation adenoidectomy and traditional curettage techniques.
\end{abstract}

Results: One hundred twenty-two patients with symptomatic adenoid hypertrophy such as nasal obstruction, snoring, and mouth breathing were included in our study. Patients underwent adenoidectomy either traditional curettage adenoidectomy (60 patients as group A) or endoscopic assisted suction coagulation adenoidectomy (62 patients as group B). Patients were scheduled for follow-up visits with respect to operative time, operative and postoperative complications. The mean age of groups $A$ and $B$ were $6.57+2.8$ and $7+2.8$ ranging from 3 to 12 years. There was a statistically significant difference between groups as regard intraoperative blood loss, trauma, postoperative complications as neck stiffness and bad odor plus postoperative endoscopic and radiological grading after the operation.

Conclusions: Suction coagulation diathermy adenoidectomy is alternative to cold adenoidectomy with significantly fewer intraoperative complications such as blood loss and trauma of prevertebral muscle plus post-operative complications such as primary or secondary bleeding and rhinolalia aperta.

Keywords: Adenoidectomy, Curettage, Suction coagulation, Diathermy

\section{Background}

Adenoidal hypertrophy is a common condition in children and can cause symptoms such as mouth breathing, nasal discharge, snoring, sleep apnea, and hyponasal speech.

It also contributes to the pathogenesis of rhinosinusitis, recurrent otitis media, and otitis media with effusion. Adenoidectomy is one of the most common procedures performed in children today, either alone or in

*Correspondence: rehab.gad77@yahoo.com

Department of Otorhinolaryngology, Menoufia University, Shibin el Kom, Egypt conjunction with tonsillectomy or insertion of ventilating tubes $[1,2]$.

The conventional adenoidectomy was developed in the pre-endoscopic era. This conventional curettage technique has some disadvantages. When the adenoid tissue has intranasal extension, this technique would be insufficient. Uncontrolled and excessive resection of adenoid tissue with a sharp curette may damage the pre-vertebral muscles. The risk of velopharyngeal insufficiency is also increased with any aggressive blind curettage $[3,4]$.

Although still widely performed, recent studies have shown that the greatest disadvantage of this method is the incomplete removal of all adenoid tissue because it is 
not correctly visualized. The improved visualization enables the surgeon to remove choanal adenoids, which are present in $10 \%$ of patients after traditional blind curettage adenoidectomy $[5,6]$.

Canon et al, popularized Endoscopic Assisted Adenoidectomy calling it "a natural progression of endoscopic technology to allow a more complete adenoidectomy". They followed a conventional transoral adenoidectomy with endoscopic removal of residual adenoids. More recently, with the advent of sinonasal endoscopy, it has become possible to remove adenoid tissue under direct visualization, with greater control of the procedure and the tissue to be removed $[7,8]$.

Suction coagulation is a combination of monopolar diathermy and suction to perform a controlled resection of the adenoids in a near bloodless field. A clear view of the entire resection is obtained with a mirror or endoscope. There is minimal blood loss and the postoperative hemorrhage rate is extremely low. Up till now, doubts remain about which surgical technique is ideal or best suited for performing adenoidectomy. The aim of this study is to evaluate and compare endoscopic assisted suction coagulation adenoidectomy and traditional curettage techniques $[9,10]$.

\section{Methods}

This prospective randomized study was conducted on 122 patients with symptomatic adenoid hypertrophy such as nasal obstruction, snoring, and mouth breathing. Using computer-generated sequence patients were divided by simple randomization technique into 2 groups: group A consists of patients (60 cases) who underwent endoscopic assisted suction coagulation adenoidectomy, while group B consists of patients (62 cases) who underwent traditional curettage adenoidectomy.

Inclusion criteria were patients between the age group of 3-12 years with symptomatic adenoid hypertrophy, the patient who was cooperative for assessment with nasal endoscopy, and children with sleep-disordered breathing due to adenoid hypertrophy. Exclusion criteria were patients indicated for tonsillectomy or ventilation tube insertion, patients with congenital nasal or maxillofacial anomalies such as cleft lip and palate, choanal atresia, retrognathia, or macrognathia, or any patient with debilitating disease or considered unfit for surgery.

All patients had a preoperative assessment in form of detailed history taking, clinical examination, and routine investigations (Complete Blood Count and bleeding profile). Endoscopic nasal and nasopharyngeal examination and grading of the adenoid were done for all cases using 0-degree rigid (2.7 $\mathrm{mm}$ diameter, $16 \mathrm{~cm}$ length) nasal endoscope (KARL STORZ, Germany) after the use of cotton buds impregnated with a local nasal decongestant
(Xylomethazoline Hydrochloride $0.1 \%\left(\right.$ Otrivin $\left.^{\mathrm{TM}}\right)$ ) and anesthesia (Lidocaine Hydrochloride 2\% (Xylocaine $^{\mathrm{TM}}$ )) for 5 min prior to the procedure. This grading system was proposed by Parikh et al. in 2006 according to the extent of adenoid tissue as following: type I for adenoid tissue no touching any anatomical structure; types II, III, and IV for adenoid tissue reaching up to either the torus tubaris, the vomer, or up to soft palate at rest consequently. Radiological evaluation of the adenoid by the percentage of soft shadow at the nasopharynx in X-ray lateral view as Cohen and Konak either mild (below 25\%), moderate (50-75\%), or severe (over $75 \%$ ) grades. Audiological evaluation of the middle ear was done by tympanogram (Welch Allyn TM286, USA) with type A [11, 12].

Every patient was positioned at Rose position (each patient lied supine with head extended by pacing a small pillow beneath the shoulders). Anesthesia was induced with propofol $(2-3 \mathrm{mg} / \mathrm{kg})$ mixed with lidocaine $(1-2$ $\mathrm{mg} / \mathrm{ml}$ ). Inhalational or intravenous agents were used for the maintenance of anesthesia. Desflurane was preferred because it has a lower amount of intraoperative bleeding and better awakening than sevoflurane during adenoidectomy operations. Tracheal intubation was facilitated using a depolarizing or nondepolarizing muscle relaxant taking the duration of surgery into consideration. Cuffed endotracheal tubes were preferred for obvious reasons, being it prevents aspiration of blood and dislodgement of the tube.

Boyle-Davis mouth gag was applied, the palate was palpated to exclude a potential submucosal cleft palate, the posterior and lateral pharyngeal walls were palpated for pulsations, to exclude a potential aberrant carotid artery, and palpation of the adenoid tissue is done.

In group A (traditional curettage adenoidectomy): Using St Clair Thompson adenoid curette, adenoidectomy was done. Hemostasis was managed by putting a gauze pack in the nasopharynx.

In group B (suction coagulation adenoidectomy): A 70-degree rigid endoscope was placed through the oropharynx and used to examine the nasopharynx, visualize and assess the adenoidal tissue. Then the malleable suction coagulator was inserted into the nasopharynx passing through the mouth, behind the elevated soft palate, and in the endoscopic field. The suction coagulator tip was placed on the adenoidal tissue and the monopolar diathermy current (SURTRON 200, USA) (Setting; Max output power SOFT COAG 90W - 100O, working frequency $600 \mathrm{kHz}$, Coagulation) was applied simultaneously with suction. The suction coagulator tip was then slowly moved to remove the whole adenoid tissue under vision guided by the endoscope. The adenoid tissue was removed by a combination of diathermy-induced coagulation and suction. 
Patients were recorded for (1) Operative time after the end of fixation of the endotracheal tube till the end of the hemostasis. (2) Intraoperative complications as trauma and blood loss. N.B. The amount of blood loss was calculated depending on that all the blood loss was collected either in the suction bottle or in cotton and gauze. All the soiled gauzes and cotton balls together with unused cotton balls are placed on the physical balance and weighed. The difference in weights is the weight of blood lost in cotton and gauze. Then we subtracted the amount of saline used in the irrigation.

Post-operative complications were recorded as (1) early complications (within 2 weeks) as reactionary bleeding, bad odor, neck stiffness, and secondary bleeding; and (2) late complications (after 2 weeks) as rhinolalia aperta and recurrence. Postoperative endoscopic nasal re-assessment of the nasopharynx and the adenoid and tympanogram will be done at 3 and 6 months postoperatively. Radiological re-evaluation of the adenoid at 6 months postoperatively.

After collecting the data, the statistical analysis was performed using Excel 2017 and SPSS software (version
15.0, SPSS, Inc., Chicago, Illinois). The variables were measured using mean and standard deviation (Mean $\pm \mathrm{SD})$. They were compared using the percentage. The categorical variables were compared using a chi-square test and Student's $t$ test. $P$ values of 0.05 were statistically significant based on the Bonferroni correction.

\section{Results}

A total of 122 patients (group $A=60$ patients, group $B=$ 62 patients) were considered in our study underwent adenoidectomy, 52 patients were male, and 70 patients were female. Group A underwent surgical adenoidectomy by curettage, and group B underwent adenoidectomy by suction coagulation diathermy. Table 1 shows that the mean age of group A was $6.57 \pm 2.8$, while in group B, the mean age was $7 \pm 2.8$.

Preoperative assessment of patients by nasal endoscope zero-degree endoscope or X-ray grading showed non-significant differences between both groups (Table 2).

Table 3 shows a highly statistically significant difference ( $p$ value $<0.001$ ) between studied groups as regards bleeding volume. This table also shows statistically

Table 1 Demographic data

\begin{tabular}{|c|c|c|c|c|c|c|c|}
\hline \multicolumn{2}{|c|}{ Demographic data } & \multicolumn{2}{|l|}{ Group $A(N=60)$} & \multicolumn{2}{|c|}{ Group B $(N=62)$} & \multirow{2}{*}{$\begin{array}{l}\text { Stat. test } \\
T=0.59\end{array}$} & \multirow{2}{*}{$\frac{P \text { value }}{0.553 \text { NS }}$} \\
\hline Age & Mean \pm SD & $6.57 \pm 2.8$ & & $7 \pm 2.8$ & & & \\
\hline & Range & $3-12$ & & $3-12$ & & & \\
\hline \multirow[t]{2}{*}{ Sex } & Male & 24 & $40 \%$ & 28 & $46.7 \%$ & $X^{2}=2.961$ & 0.564 NS \\
\hline & Female & 36 & $60 \%$ & 34 & $53.3 \%$ & & \\
\hline
\end{tabular}

$X^{2}$ : Chi-square test, $T:$ Student's $t$ test, NS: $p$ value $>0.05$ is considered non-significant

Table 2 Pre-operative endoscopic and radiological grading

\begin{tabular}{llllllll}
\hline Preoperative grading & & Group A & \multicolumn{3}{l}{ Group B } & Stat. test & P value \\
\hline Endoscopic grading & Grade III & 26 & $43.3 \%$ & 27 & $43.3 \%$ & $X^{2}=0.419$ & 0.981 NS \\
& Grade IV & 34 & $56.7 \%$ & 35 & $56.7 \%$ & & \\
X-ray grading & Grade II & 16 & $26.7 \%$ & 19 & $30.6 \%$ & $X^{2}=3.655$ & 0.455 NS \\
& Grade III & 44 & $73.3 \%$ & 43 & $69.4 \%$ & & \\
\hline
\end{tabular}

$X^{2}$ : Chi-square test, NS: $p$ value $>0.05$ is considered non-significant

Table 3 Intraoperative complications

\begin{tabular}{|c|c|c|c|c|c|}
\hline \multicolumn{2}{|c|}{ Intraoperative complications } & \multirow{2}{*}{$\begin{array}{l}\begin{array}{l}\text { Group A } \\
(\boldsymbol{N}=\mathbf{6 0})\end{array} \\
49.7 \pm 9.05\end{array}$} & \multirow{2}{*}{$\begin{array}{l}\begin{array}{l}\text { Group B } \\
(\boldsymbol{N}=\mathbf{6 2})\end{array} \\
4.53 \pm 1.16\end{array}$} & \multirow{2}{*}{$\begin{array}{l}\text { Stat. test } \\
T=27.08\end{array}$} & \multirow{2}{*}{$\begin{array}{l}P \text { value } \\
<0.001 \mathrm{HS}\end{array}$} \\
\hline Blood loss (ml) & Mean \pm SD & & & & \\
\hline & Range & $40-80$ & $3-6$ & & \\
\hline \multirow[t]{2}{*}{ Trauma } & No & $56(93.3 \%)$ & $62(100 \%)$ & $x^{2}=10.104$ & $0.039 \mathrm{~S}$ \\
\hline & Yes & $4(6.7 \%)$ & 0 & & \\
\hline
\end{tabular}

$X^{2}$ : Chi-square test, NS: $p$ value $>0.05$ is considered non-significant, $S: p$ value $>0.05$ is considered significant, HS: $p$ value $>0.001$ is considered highly significant 
significant differences between studied groups as regards blood loss and trauma.

Table 4 showed statistically significant differences between both groups in early postoperative complications within a week after operations as reactionary bleeding, neck stiffness, and bad odor.

Table 5 shows a non-statistically significant difference between studied groups as regard rhinolalia aperta. This table shows a statistically significant difference between studied groups as regard recurrence.

The difference between both groups is statistically significant as regard postoperative endoscopic assessment and X-ray grading at the 6th month after operation (Table 6).

\section{Discussion}

Recent techniques for adenoidectomy are based on the principle of adequate removal of the adenoids with fewer complications as damage to the surrounding structures, such as the torus tubarus, the palate, the posterior pharyngeal wall, and the choana. In our study, 60 patients of group A underwent endoscopic assisted suction coagulation adenoidectomy, while 62 patients of group B underwent traditional curettage adenoidectomy $[10,13]$.

The nasal endoscopes and nasopharyngeal X-ray were used in this study for grading of adenoid in preoperative assessment of adenoid as in Wynn et al. (2003) who used nasal endoscopy to determine preoperative choanal obstruction by adenoid. In our study, there were 26 patients (43.3\%) who had grade (III) adenoid and 34 patients $(56.7 \%)$ had grade (IV) adenoid in group A, while in group B there were 27 patients $(43.3 \%)$ who had grade (III) adenoid and 35 patients (56.7\%) had grade (IV) adenoid. Preoperative X-ray grading of adenoid showed that there were 16 patients $(26.7 \%)$ had grade (II) and 44 patients $(73.3 \%)$ had grade (III) in group A, while in group B, there were 19 patients $(30.6 \%)$ who had grade (II), and 43 patients (69.4\%) had grade (III) [10].

The conventional curettage technique showed more abundant intraoperative blood loss and was about 49.47

Table 4 Early postoperative complications

\begin{tabular}{|c|c|c|c|c|c|c|c|}
\hline \multicolumn{2}{|c|}{ Early postoperative complications } & \multicolumn{2}{|c|}{ Group A $(N=60)$} & \multicolumn{2}{|c|}{ Group $B(N=62)$} & \multirow{2}{*}{$\begin{array}{l}\text { Stat. test } \\
X^{2}=10.104\end{array}$} & \multirow{2}{*}{$\begin{array}{l}P \text { value } \\
0.039 \mathrm{~S}\end{array}$} \\
\hline Reactionary bleeding & No & 56 & $93.3 \%$ & 62 & $100 \%$ & & \\
\hline & Yes & 4 & $6.7 \%$ & 0 & 0 & & \\
\hline \multirow[t]{2}{*}{ Neck Stiffness } & No & 56 & $93.3 \%$ & 46 & $74.2 \%$ & $x^{2}=15.199$ & $0.004 \mathrm{~S}$ \\
\hline & Yes & 4 & $6.7 \%$ & 16 & $25.8 \%$ & & \\
\hline \multirow[t]{2}{*}{$2^{\text {ry }}$ bleeding Bleed (post) } & No & 56 & $96.7 \%$ & 61 & $98.4 \%$ & $x^{2}=6.589$ & $0.159 \mathrm{NS}$ \\
\hline & Yes & 4 & $3.3 \%$ & 1 & $1.6 \%$ & & \\
\hline \multirow[t]{2}{*}{ Bad odor } & No & 60 & $100 \%$ & 45 & $72.6 \%$ & $x^{2}=28.029$ & $0.0001 \mathrm{HS}$ \\
\hline & Yes & 0 & $0 \%$ & 17 & $27.4 \%$ & & \\
\hline
\end{tabular}

$X^{2}$ : Chi-square test, NS: $p$ value $>0.05$ is considered non-significant, S: $p$ value $>0.05$ is considered significant, HS: $p$ value $>0.001$ is considered highly significant

Table 5 Late postoperative complications

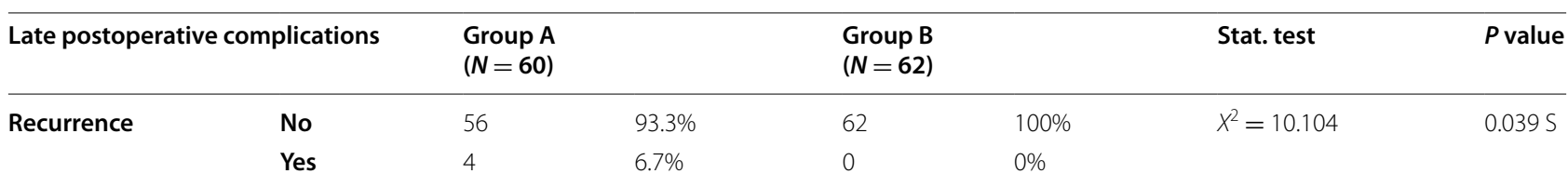

$X^{2}$ : Chi-square test, NS: $p$ value $>0.05$ is considered non-significant, $\mathrm{S}: p$ value $>0.05$ is considered significant, HS: $p$ value $>0.001$ is considered highly significant

Table 6 Postoperative endoscopic grading (after 6 months) and radiological grading (after 6 months)

\begin{tabular}{|c|c|c|c|c|c|c|c|}
\hline \multicolumn{2}{|l|}{ Postoperative grading } & \multicolumn{2}{|c|}{ Group A $(N=60)$} & \multicolumn{2}{|c|}{ Group B $(N=62)$} & \multirow{2}{*}{$\begin{array}{l}\text { Stat. test } \\
X^{2}=10.104\end{array}$} & \multirow{2}{*}{$\frac{P \text { value }}{0.039 \mathrm{~S}}$} \\
\hline Endoscopic (after 6 months) & $\mathrm{I}$ & 51 & $85 \%$ & 62 & $100 \%$ & & \\
\hline & II & 3 & $5 \%$ & 0 & $0 \%$ & & \\
\hline & III & 6 & $10 \%$ & 0 & $0 \%$ & & \\
\hline \multirow[t]{2}{*}{ X-ray (after 6 months) } & $\mathrm{I}$ & 56 & $93.3 \%$ & 62 & $100 \%$ & $X^{2}=10.104$ & $0.039 \mathrm{~S}$ \\
\hline & II & 4 & $6.7 \%$ & 0 & $0 \%$ & & \\
\hline
\end{tabular}

$X^{2}$ : Chi-square test, NS: $p$ value $>0.05$ is considered non-significant, S: $p$ value $>0.05$ is considered significant, HS: $p$ value $>0.001$ is considered highly significant 
$\pm 9.05 \mathrm{ml}$. This agrees with Torantino et al. (2004) with $46.25 \mathrm{ml}$ of intraoperative blood loss. In contrast with our study, the conventional curettage technique, as regard intraoperative blood loss was fewer in Datta Et al. (2009) with $21 \mathrm{ml}$. Suction coagulation adenoidectomy showed less intraoperative blood loss in our study that was 4.53 $\pm 1.16 \mathrm{ml}$. As well Reed et al. (2009) conducted the same results about blood loss in the suction diathermy technique (mean $4.1 \mathrm{ml}$ ) [14-16].

As well as in our study, El-Maghraby et al. (2018) detected that there were high significant statistical differences according to intraoperative blood loss between conventional (43.45 $\mathrm{min}$ ) and suction diathermy techniques $(5.56 \mathrm{ml})$ [17].

No trauma was recorded in Group A of our study, while in group B 4 patients only $(6.7 \%)$ had trauma in prevertebral muscle. This may be due to the invisibility of the field. Torantino et al. (2004) showed also significantly less iatrogenic trauma to prevertebral muscle using suction coagulation adenoidectomy [14].

Our results showed that only 4 patients (6.7\%) had primary bleeding in group A, but in group B, there was no reactionary bleeding. Two patients presented with primary bleeding due to a tear of paravertebral muscle and torus. Cauterization was done by suction and bipolar diathermy to control reactionary bleeding. That means a statistically significant difference ( $p$ value $>0.05$ ) between studied groups as regard primary bleeding. This was agreed by Torantino et al. (2004) [14].

In group A, there were 4 patients who only had neck stiffness within two weeks after the operation. While in group $\mathrm{B}$, there were 16 patients who had neck stiffness within two weeks after the operation. So, the difference between the two groups is significant as regards postoperative neck stiffness. Postoperative neck stiffness in a study conducted by Owen et al. (2015) was reported in a non-randomized controlled trial of 276 patients treated by suction diathermy, curettage, or microdebrider adenoidectomy to have occurred in $9 \%(8 / 93), 10 \%(8 / 84)$, and $17 \%(17 / 99)$ of patients, respectively $(p=0.08)$ [18].

In group $\mathrm{A}$, there were no cases presented with bad odor post-operative, but in group B there were 17 patients who had bad odor postoperatively. It agreed with Soumya et al. (2019) who reported halitosis occurs with suction coagulation adenoidectomy, it appears on the 2nd day post-operative and disappears 7 days postoperative [19].

Secondary bleeding in our study occurred in group A with four cases within 2 weeks after the operation, but there was only one case with secondary bleeding in group B. As well as Ark et al. (2010) reported that no postoperative bleeding occurred using regard suction coagulation adenoidectomy, but it occurred with $10 \%$ of cases operated by conventional curettage technique in a nonrandomized controlled trial of 149 patients [8].

There is a randomized controlled trial presented by Ark et al. (2010). It included 100 patients treated using curettage adenoidectomy (group A) or suction diathermy adenoidectomy (group B) reported that group B had significantly fewer grading for remnant adenoids at 6 -month follow-up $(p=0.0184)$. This agrees with our results about recurrence that was confirmed with postoperative endoscopic assessment and X-ray adenoid grading after 6 months. So, the difference between the two groups is statistically significant as regards postoperative adenoid assessment at the 6th month after the operation ( $p$ value $>0.05)$ [8].

A total of 27 children underwent suction diathermy adenoidectomy in a study conducted by Venkataramani $\mathrm{N}$ et al. (2019); none of the patients had postoperative bleeding. There was no pain related to adenoidectomy was recorded with any studied patients. The follow-up period for the included patients ranged from 3 months to 3 years. On postoperative assessment, most of the patients (25 out of 27) had no mouth breathing or nasal discharge with a score of 0 , two patients had occasional mouth breathing with a score of 1 , and one of these had an occasional nasal discharge. One of the patients who had occasional mouth breathing had deviated nasal septum on repeat postoperative endoscopy [20].

Ark et al. (2010) evaluated the use of endoscopy for the visualization of the removed adenoid tissue after the "blind curettage" was performed. The conventional technique was associated with high incidence of residual adenoid tissue. The mean percentage of residual tissue was approximately $20 \%$, especially in the peri-tubal and the choanal arch regions [8].

Oztürk and Polat (2012) reported that the conventional technique can be inadequate. Uncontrolled and excessive resection of adenoid tissue with a sharp curette may damage prevertebral muscles. The risk of velopharyngeal insufficiency is also increased with an aggressive blind adenoidectomy [21].

\section{Conclusion}

All parameters of comparison between traditional curettage adenoidectomy and suction coagulation adenoidectomy in our prospective randomized study direct us to ensure that suction coagulation diathermy adenoidectomy is alternative to cold adenoidectomy with a significant decrease of intraoperative blood loss and trauma of prevertebral muscle. Post-operative complications decrease as primary bleeding, bad odor, secondary bleeding, and recurrence of adenoid tissues.

Acknowledgements

Not applicable 


\section{Authors' contributions}

Audiological tests were interpreted by the audiology department in the hospital. All operations were done by RG under supervision of MK. ME and AA shared in data collection and in writing the manuscript. YK revised the manuscript and add major modifications. All authors finally read and approved the final manuscript.

\section{Funding}

There was no funding.

\section{Availability of data and materials}

The datasets used and/or analyzed in the current study are available from the corresponding author on reasonable request.

\section{Declarations}

\section{Ethics approval and consent to participant}

Ethics approval and consent to participate: A written consent was taken from all participants according to the ethical committee of Menoufia University, the ethics committee reference number is 5/2020ENT/112. Informed written consent to participate in the study was provided by all participants' parent or legal guardian in the case of children under 16.

\section{Consent of publication}

Not applicable

\section{Competing interests}

The authors declare that they have no competing interests.

Received: 16 July 2021 Accepted: 30 September 2021

Published online: 24 November 2021

\section{References}

1. Pathan F, Sudarshan K, Satpathy S (2016) Endoscopic Adenoidectomy using a microdebrider: a series of 20 cases. Int J Curr Med Appl Sci 11(2):116-118

2. Emerick KS, Cunningham MJ (2006) Tubal tonsil hypertrophy: a cause of recurrent symptoms after adenoidectomy. Arch Otolaryngol Head Neck Surg 132(2):153-156

3. Ferreira MS, Gomes MJ, Ximendes R, Evangelista AR, Miranda EL, Garcia LB et al (2018) Comparison of three different adenoidectomy techniques in children-has the conventional technique been surpassed? Int J Pediatr Otorhinolaryngol 104:145-149

4. Ruben RJ (2017) The adenoid: its history and a cautionary tale. Laryngoscope. 127(2):513-528

5. Pagella F, Pusateri A, Canzi P, Caputo M, Marseglia A, Pelizzo G et al (2011) The evolution of the adenoidectomy: analysis of different power-assisted techniques. Int J Immunopathol Pharmacol 24(4):55-59
6. Dhanasekar G, Liapi A, Turner N (2010) Adenoidectomy techniques: UK survey. J. Laryngol. Otol. 124(2):199-203

7. Cannon CR, Replogle WH, Schenk MP (1999) Endoscopic-assisted adenoidectomy. Otolaryngol Head Neck Surg 121:740-744

8. Ark N, Kurtaran H, Ugur KS, Yilmaz T, Ozboduroglu AA, Mutlu C (2010) Comparison of adenoidectomy methods: examining with digital palpation vs. visualizing the placement of the curette, Int. J. Pediatr. Otorhinolaryngol. 74(6):649-651

9. Kim JW, Kim HJ, Lee WH, Kim DK, Kim SW, Kim YH et al (2015) Comparative study for efficacy and safety of adenoidectomy according to the surgical method: a prospective multicenter study. PloS one. 10(8):e0135304

10. Wynn R, Rosenfeld RM (2003) Outcomes in suction coagulator adenoidectomy. Arch Otolaryngol Head Neck Surg. 129(2):182-185

11. Parikh S, Coronel M, Lee J, Brown S (2006) Validation of a new grading system for endoscopic examination of adenoid hypertrophy. Otolaryngology Head Neck Surg 135(5):684-687

12. Cohen ML, Koltai PJ, Scott JR (1992) Lateral cervical radiographs and adenoid size: Do they correlate? Ent J 71(12):638-642

13. Yang L, Shan Y, Wang S, Cai C, Zhang H (2016) Endoscopic Assisted Adenoidectomy Versus Conventional Curettage Adenoidectomy: a MetaAnalysis of Randomized Controlled Trials. Springer Plus. 5:426

14. Tarantino V, D'Agostino R, Melagrana A (2004) Safety of electronic molecular resonance adenoidectomy. Int J Pediatr Otorhinolaryngol 68(12):1519-1523

15. Datta R, Singh VP (2009) Deshpal. conventional versus endoscopic powered adenoidectomy: a comparative study. Med J Armed Forces India 65(4):308-312

16. Reed J, Sridhara S, Brietzke S (2009) Electrocautery adenoidectomy outcomes: A meta-analysis. Otolaryngol Head Neck Surg 56(3):534-344

17. El-Maghraby AA, El-Habashy HS, Ahmed HA (2018) Adenoidectomy by different techniques. Al-Azhar Med. J. 47(4):699-709

18. Owens D, Jaramillo M, Saunders M (2015) Suction diathermy adenoid ablation. J Laryngol Otol. 119(1):34-35

19. Soumya S, Vissapragada R, Le J, Ooi EH (2019) Halitosis and Pain Post Electrocautery Adenoidectomy. Medicina (Kaunas). 55(6):312

20. Venkataramani N, Sachidananda R, Dachuri S, Vasishta SR (2019) Suction diathermy adenoidectomy: audit of current practice in a tertiary care hospital. Int J Otorhinolaryngol Head Neck Surg. 5(6):1611-1614

21. Ozturk O, Polat \$̧ (2012) Comparison of transoral power-assisted endoscopic adenoidectomy to curettage adenoidectomy. Advances in therapy. 22:1-14

\section{Publisher's Note}

Springer Nature remains neutral with regard to jurisdictional claims in published maps and institutional affiliations.

\section{Submit your manuscript to a SpringerOpen ${ }^{\circ}$ journal and benefit from:}

- Convenient online submission

- Rigorous peer review

- Open access: articles freely available online

- High visibility within the field

- Retaining the copyright to your article

Submit your next manuscript at springeropen.com 